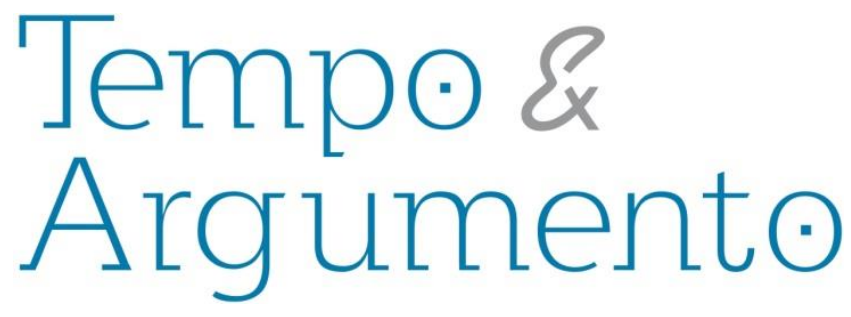

\title{
História e estética n'A COISA: Representações visuais do corpo na imprensa ilustrada da Bahia sobre abolição e pós-abolição
}

\begin{abstract}
Resumo
Este artigo propõe analisar as formas como o corpo humano foi representado em duas imagens publicadas no impresso baiano A Coisa, com o uso da técnica xilogravura, e uma imagem publicada na revista norte-americana The Verdict. A madeira, a tinta, a cor e o papel são elementos que, ao comporem imagens gravadas de corpos e cenários, demarcam características fenotípicas e a consequente ressignificação das identidades representadas. Assim, os materiais, os suportes e as técnicas utilizadas na produção e veiculação das imagens publicadas na imprensa ilustrada entre o final do Império e a Primeira República no Brasil, tornam-se elementos de interesse ao possibilitarem a identificação de uma linguagem visual, capaz de produzir e veicular discursos étnicos, raciais, culturais, sociais e políticos ao mesmo tempo em que constituem visualidades para esses corpos.
\end{abstract}

Palavras-chave: Imprensa. Ilustrações. Corpo humano. Negros. Xilogravura. Brasil - História - República Velha, 1889-1930.

\section{Túlio Henrique Pereira}

Doutor em História Social pela Universidade Federal de Uberlândia (UFU). Estágio Pós-Doutoral na Universidade Federal do Piauí (UFPI). Bolsista PNPD/CAPES.

Teresina - PI - Brasil

tuliohenriquepereira@gmail.com

\section{Francisco de Assis de Sousa Nascimento \\ Doutor em História Social pela Universidade Federal Fluminense (UFF). Estágio Pós-Doutoral na Pontifícia Universidade Católica de São Paulo (PUC/SP). Professor da Universidade Federal do Piauí (UFPI). Teresina - PI - Brasil franciscoufpi@gmail.com}

\section{Para citar este artigo: \\ PEREIRA, Túlio Henrique; NASCIMENTO, Francisco de Assis de Sousa. História e estética n'A COISA: Representações visuais do corpo na imprensa ilustrada da Bahia sobre abolição e pós-abolição. Tempo e Argumento, Florianópolis, v. 10, n. 25, p. 09 - 37, jul./set. 2018.}


History and Aesthetics in A

COISA: visual representations

of the body in the illustrated

press of Bahia about abolition

\title{
and post-abolition
}

\begin{abstract}
This article proposes to analyze the way in which the human body was represented in two images from Bahia's newspaper A Coisa, observing the way the woodcut technique was used, and an image from the North American's magazine The Verdict. The wood, the ink, the color and the paper comprise elements responsible for the creation of the engraved images of bodies and scenes. These representations of bodies and sceneries mark particular phenotypic characteristics and results in a continued process of identities resignification. The objects, the holders frames and the techniques used in this process and the propagation of images at illustrated press between the final ages of the Empire and the First Brazilian Republic become important elements able to identify a visual language, and able to produce ethnic, racial, social and political speeches, while composing visualities for these represented bodies.
\end{abstract}

Keywords: Press. Illustrations. Human Body. Black. Woodcut. Brazil - History - Old Republic, 1889-1930.

\section{Representação do corpo e produção das imagens}

Entendemos que a representação visual ou metafórica do corpo humano ao longo de gerações imprime os modos de ver e as experiências de seus autores. A prática da representação plástica do corpo não apenas sofreu a influência da memória vivida de seus produtores, mas também esbarrou em questões técnicas limitantes ou facilitadoras no ato de pintar, escavar sulcos em rochas e madeira, desenhar sobre o papel, fotografar, 
esculpir ou riscar sobre pedras ou folhas de metal os delineios das silhuetas, ao oferecer formas identitárias e composições étnicas relacionadas à cor e aos fenótipos desses corpos representados, ou seus aspectos culturais a partir da representação das vestimentas, e também propagar imaginários e sentidos para a ressignificação e manutenção dos valores de belo e feio na cultura das visualidades com motivos humanos.

O filósofo francês Yves Michaud escreveu sobre a prática de representação do corpo humano no livro História do corpo: as mutações do olhar - o século XX, organizado por Alain Corbin, Jean-Jacques Courtine e Georges Vigarello. Compreendemos a partir do texto de Michaud, que o corpo humano, transplantado para sua representação visual, seja em forma de desenho, pintura, gravura, grafite, escultura ou fotografia, adquire personalidade por estar condicionado à temporalidade de quem produz sua representação. Esse corpo, visualmente representado, contém elementos naturais de sua substancialidade biológica e técnica, ou seja, a imagem se torna um objeto de clivagem, atravessada pelos sentidos de quem a serviu como inspiração e de quem a produziu.

Ainda segundo Yves Michaud, foi entre os anos 1840 e 1860 que a imagem experimentou mudanças significativas em sua forma de representação, por meio da técnica da fotografia (MICHAUD, 2008). De acordo com o autor, essas mudanças provocaram abalos na relação entre o corpo e a imagem, considerando que a fotografia permitiu apreender os modelos com mais agilidade e eficiência do que as pinturas feitas pelos artistas plásticos em seus ateliês. Essa eficiência seria responsável pela transformação da representação da pose, das práticas de modelagem, das nuances, dos matizes e das novas habilidades com as quais esses corpos passaram a contar.

Reconhecidas como sendo um repertório autêntico e de qualidade, as imagens xilográficas, litográficas e os clichês fluminenses assinados por nomes que ficaram famosos no Brasil na década de 1880, tais como Angelo Agostini, Pereira Neto, Vale e Pedro Américo provocaram a segmentação e a generalização da caricatura produzida no Brasil, especialmente no que se refere ao estilo de Angelo Agostini, responsável por influenciar positivamente seus contemporâneos. O fato negativo da influência foi, segundo Herman Lima, um grande período de efetiva homogeneização do estilo (LIMA, 1963). Desse modo caricaturistas de fora do território fluminense passaram a desenhar 
e/ou entalhar suas imagens, sob a influência do padrão Agostini e/ou fluminense de produção de caricaturas. Assim levantamos a questão acerca do fato que esse repertório de imagens não apenas influenciou caricaturistas de territórios externos ao cenário do Rio de Janeiro na década de 1880, mas também consideramos o fato de, por muitas décadas, os historiadores das imagens no Brasil, se voltarem apenas para a excelência dessas imagens fluminenses, preterindo produções mais artesanais, como muitas produções visuais da imprensa ilustrada na Bahia, soterrando nomes como Arthur Arezio da Fonseca, Fortunato Soares dos Santos e Gavarni.

Consideramos dentro da complexidade do contexto histórico e social do final do século XIX e início do XX, que as imagens dos corpos brancos e negros em caricaturas publicadas em jornais do território do Salvador contribuem, na contemporaneidade, para a manutenção de uma visão de memória de um passado residual no presente; de modo a apresentar as tensões relacionadas à abolição da escravatura e a instauração da República no Brasil. Percebemos desse modo, que essas imagens produziram um imaginário para a compreensão pejorativa e racializada dos corpos negros, tidos enquanto memórias coletivas, marginais e homogêneas. Essas imagens que enfatizam os tipos físicos comuns de negros se convergiram mnemonicamente de modo a opacizar a pluralidade étnica brasileira, sendo responsável por difundir uma memória coletiva antagônica da diversidade e multiplicidade étnica identificada como branca, seus costumes socioculturais baseados nos valores clássico-europeus, passando a significar as considerações sobre o fenótipo do corpo e o matiz da pele, tomados enquanto valor.

A partir do discurso filosófico de Edmund Burke no ensaio Uma investigação filosófica sobre a origem de nossas ideias do sublime e do belo que se compreendeu o belo enquanto um conceito inerente da atividade sensorial humana, sendo este, antecessor e capaz de atribuir marcas e ressaltar nos homens valores que se tornaram meios de identificação a partir do jogo de percepções entre o Eu e o Outro numa perspectiva schopenhauriana, sem a possibilidade do exercício da alteridade. Edmund Burke apresenta o homem europeu enquanto um juiz dotado da capacidade de codificar e julgar o mundo a sua volta, e definir a seu modo o Outro, tomado como um animal dotado da 
capacidade do gosto ${ }^{1}$, do pensar e da reflexão, e historicamente compreendido enquanto sujeito no núcleo social. É ainda neste ensaio que Burke (1729-1797) faz um paralelo investigativo e filosófico entre os conceitos de belo e sublime com o objetivo de “descobrir se existem quaisquer princípios segundo os quais a imaginação é afetada e que sejam tão comuns a todos os homens, tão fundamentados e tão seguros que possam fornecer os meios para sobre eles se raciocinar" (BURKE, 1993, p. 23).

A discussão suscitada a partir da leitura do ensaio nos levou a pensar a relevância do estudo em torno das ideias sobre o belo apresentadas pelo autor como também a necessidade de se problematizar a naturalidade com que denominamos a beleza e seus valores atribuídos aos corpos humanos, à arquitetura, e aos animais no discurso comum da contemporaneidade, sem o questionamento da origem de suas definições, imbricadas aos valores socioculturais europeus difundidos na modernidade por meio da mercantilização, da expansão marítima portuguesa e espanhola e, consequentemente, pelo colonialismo da África e das Américas.

Ao partir da obra de Edmud Burke foi possível relatar um breve histórico sobre o belo e o que pode se considerar como uma das primeiras evidências sócio-históricas e filosóficas a tratar do discurso em torno dos valores de beleza e dos sentidos de beleza enquanto condicionantes naturais e regulares do gênero humano. Evidências essas retomadas a posteriori nos estudos em torno das concepções do belo ${ }^{2}$ e dos juízos de gosto, assinados por Immanuel Kant. Para Kant, a estética do belo é um estado de vida de direito próprio, uma capacidade de fruição intimamente relacionada a outras capacidades

\footnotetext{
${ }_{1}^{1}$ Para Burke (1993 [1757], p. 22) o termo gosto, não pode ser definido em exatidão, pois ele estaria distante de ser uma ideia simples e determinada no espírito da maioria dos homens e, portanto, está sujeito à indefinição e à confusão.

2 "O adjetivo qualifica o que concerne ao belo (emoção ou julgamento estético). O substantivo (que aparece na segunda metade do século XVIII) designa a teoria da arte e do belo, ou, mais precisamente, a disciplina cujo objeto são os julgamentos de apreciação quando se aplicam ao belo e ao feio. Embora o termo Ihes seja posterior, pode-se assinalar uma estética (metafísica) em Platão ou São Tomás. Porém, os dois sistemas mais rematados da filosofia clássica nesse domínio são o de Kant (1790) que, insistindo na finalidade interna presente na obra de arte, marca a especificidade da última, e o de Hegel (1988), que mostra que o desvendamento do significado da arte é inseparável de sua história - o que implica a eventualidade de seu fim. Tendo a estética moderna, em geral, renunciado a assinalar às normas do belo, volta as suas pesquisas seja para o estudo das próprias formas em seu desenvolvimento histórico, conforme Panofsky (1995), seja para as relações que podem existir entre uma obra e seu criador ou, mais amplamente, seu meio social, conforme propuseram os estéticos marxistas"(DUROZOI; ROUSSEL, 1996, p. 167-168).
} 
cognitivas do ser humano, sem depender da aquisição de conhecimento, ou seja, para contemplar o belo, o sujeito não se vale das determinações das capacidades cognitivas das faculdades do conhecimento (KANT, 1993 [1790]). O juízo estético kantiano chega a um conceito mínimo da percepção estética, pois, para todos os objetos, independentemente de serem eles obras de arte, ou objetos oriundos da natureza, ou objetos da vida cotidiana pública ou privada, estes possuem, minimamente, algum aspecto que se manifesta a partir da atenção que se dá a esta manifestação. Conceitos tais como objeto estético e percepção estética são, nesse sentido, indissociáveis.

No contraponto entre as considerações kantianas e as investigações filosóficas burkeanas acerca do belo, observa-se o distanciamento no que tange à estética para ambos. Pois, entendeu-se que Edmund Burke estabelece um binômio entre belo e sublime, sendo o primeiro responsável pela incitação das paixões positivas, tais como o prazer que une os homens e os conduz à perpetuação da espécie, sendo, portanto, uma qualidade social, pois conduz à criação da sociedade; e o segundo conceito, respectivamente, o responsável pela incitação das paixões no sentido negativo, provocando sentimentos de autopreservação como a dor, o terror e o medo em sua consciência da morte e da finitude. Todavia, há que se considerar que o sublime também incita uma paixão positiva: a dor positiva. Positivo, no caso, não está no valor, mas no movimento. Positivo é um movimento do estado de diferença para um estado de prazer ou de dor. Negativo seria um movimento de um estado de prazer ou de dor para o estado de indiferença. A dor negativa, portanto, é aquilo que produz o que Burke denomina “deleite", que, para ele, não se confunde com o prazer positivo. Sendo assim, a estética burkeana relaciona-se aos padrões de gosto, ou das ideias políticas que possam naturalizar uma ideia de valor comum entre os homens. No entanto, na leitura realizada das concepções kantianas, entendeu-se que este não toma a estética a partir do entusiasmo emocional das ideias coletivas dos homens, mas sim de um prazer estético subjetivo aos homens em duas concepções subjetivas inerentes ou não a sua natureza.

Segundo Umberto Eco, ao falar sobre a estética do belo na perspectiva clássica da Grécia: "Chi è bello è caro, chi non è bello non è caro", ou seja, o que é belo é caro, o que não é belo não é caro (ECO, 2004, p. 36). Percebe-se, contudo, que ao se referir aos 
versos de provérbios constantemente recordados pelos poetas gregos, entre eles Teognide e Eurípedes, Eco revela que essa forma de pensar o belo partindo de uma concepção grega não passa de uma expressão do sentido comum sobre a beleza dos antigos gregos.

Parafraseando o autor em uma tradução livre, vê-se o entendimento que, para ele, de fato, na Grécia Antiga, a beleza não tinha um estatuto autônomo, pode-se dizer que aos gregos até a Idade de Péricles faltou uma verdadeira e própria estética e uma teoria da beleza. Não por acaso, encontramos a beleza quase sempre associada à justiça, a bondade, a generosidade, bem como à medida e a conveniência. A beleza dos corpos masculino e feminino não podem, todavia, afirmar que os textos de Homero manifestaram uma compreensão concebível da beleza. O mesmo devemos dizer para os poetas líricos sucessivos, entre eles com importante exceção de Safo, o tema da beleza não parece relevante. Essa perspectiva originária não pode mais ser compreendida a não ser que se olhe para a beleza com os olhos modernos, como usualmente o fazem quando se trata de beleza clássica, sendo que esta, na realidade, era concebida de forma ficcional, uma verdadeira projeção sobre o passado de uma visão do mundo moderno.

Kalón é a significação do que dá prazer que suscita admiração, que atrai o olhar, o objeto belo é o objeto que na virtude da sua forma apaga os sentidos, entre esses em particular o olho e a orelha. No caso do corpo humano assumem um papel relevante a qualidade do corpo e da alma que vem pela percepção do olho, e pela mente, mais que do corpo, sobre essas bases podemos falar de uma primeira concepção da beleza que está mais ligada as diversas artes que a expressão e não a um estatuto unitário, embora apropriada à simetria das partes, da escultura etc. (ECO, 2004, p. 36-42, tradução nossa).

A Aesthesis, como uma dimensão própria do homem, tem despertado, desde a Grécia antiga, interesse e preocupação no ser por aquilo que, efetivamente, o agrada. Essa disposição ao questionamento do belo, a busca incessante pela compreensão e delimitação do conceito de beleza, move a estética no transpassar da vida humana como disciplina filosófica, como mera fruição, como criação, como um ideal ou como uma ruptura. Para Platão, o belo é o bem, a verdade, a perfeição; existe em si mesmo, apartado do mundo sensível, residindo, portanto, no mundo das ideias. Todavia, para o filósofo David Hume, 
quem nunca teve a oportunidade de comparar os diversos tipos de beleza, indubitavelmente se encontra completamente incapacitado de dar opinião a respeito de qualquer objeto que lhe seja apresentado. Só através da comparação podemos determinar os epítetos da aprovação ou da censura, aprendendo a discernir sobre o devido grau de cada um (HUME, 1989, p. 266).

É considerável ponderar que em Burke a beleza dos homens e dos animais não diz respeito às proporções, esta se apresenta enquanto uma qualidade distinta do sublime, “por beleza entendo aquela qualidade, ou aquelas qualidades dos corpos em virtude das quais eles despertam amor ou alguma paixão semelhante" (BURKE, 1993, p. 99).

As qualidades em torno da concepção de beleza burkeana se limitam às definições puramente sensíveis das coisas,

a fim de manter a máxima simplicidade em um assunto que [...] desvia nossa atenção, quando deduzimos aquelas várias causas de simpatia que nos ligam às pessoas ou coisas devido a considerações secundárias, e não à força positiva que elas possuem meramente por serem vistas (BURKE, 1993, p. 99).

A proporção não é, definitivamente, para o autor, a causa da beleza na espécie humana e também não é a responsável pela causa do desejo, "ao passo que a maior beleza nos homens ou em outros animais, embora desperte amor, não incita nenhum desejo" (BURKE, 1993, p. 100).

As definições de belo e sublime na obra de Burke levou a compreensão de que as cores atribuídas aos corpos mantêm uma relação natural com os sentidos de belo e feio, o que leva a considerar os valores que a arte determinou às cores ao longo das gerações, atribuindo frieza e quentura, alegria e tenacidade aos matizes. Para Burke, a um corpo belo, este nunca deverá ser revestido de uma cor escura, pois se espera sempre que este seja recoberto pela beleza dos tons mais delicados, claros, alvos e suaves.

As cores fortes e escuras não seriam belas para o autor, porém, com o hábito, poderiam deixar de provocar o terror aos olhos humanos, o terror como uma característica das reações do sublime, “em uma bela tez, nem o colorido é matizado nem as cores, como o vermelho e o branco, são vivas e lustrosas" (BURKE, 1993, p. 123). O 
efeito do preto, do negro ou escuro seria na visão burkeana sempre aterrorizante e, desse modo, sublime.

Para Edmund Burke, a dor, o terror, a finitude, a morte, a limitação e todas as sensações que nos levam às paixões negativas são reações que também podem ser suscitadas da escuridão, do negro e da cor preta; para ele, as ideias de negro e de escuridão são equivalentes (BURKE, 1993, p. 151). O autor traz uma imagem metafórica em seu ensaio, para exemplificar o espanto que um jovem cego de nascença tem ao recuperar a visão após uma cirurgia de catarata e se deparar com o corpo de uma mulher negra; para Burke, o jovem ao perceber aquele corpo negro, é tomado pelo horror.

\section{Discursos sobre a beleza na imprensa ilustrada da Bahia}

O mundo como representação existe enquanto vontade do sujeito. E esse mundo se estabelece através de sistemas dinâmicos de organização, determinados pelos sujeitos, na medida em que a organização os mantenha ou os reconstitua, respeitando as reivindicações propostas por seus próprios juízos, determinando acordos sociais para a criação de leis e, principalmente, a ética. Juntos, esses mecanismos sociais seriam, unidos, responsáveis pelo advento da memória social em seu conceito amplo, ou seja, com a propriedade de conservar informações de um conjunto de funções psico-ideológicas inerentes ao sujeito e à estrutura que ele representa. Marca, assim, suas impressões do passado e seleciona as memórias do presente, reforçadas paulatinamente para o futuro, através de práticas e da capacidade do acionamento mnemônico do pensar: lembrar e esquecer (LE GOFF, 1994).

Nessa perspectiva, verifica-se a memória como a constituição imagética dos sujeitos, determinada por suas relações com o meio e o espaço histórico, e sua ideia de mundo. Considera-se, então, toda a trama que os possa permear para estabelecer laços a partir de identificações comuns e legíveis no seio de um grupo social.

Podemos considerar que Aby Warburg pensou as imagens não com o objetivo de estabelecer o confronto entre documentos e referências heterogêneas, mas sim, possibilitando-se na busca do imperceptível, daquilo que não se faz possível apenas com a 
observação geral dos motivos que compõem uma imagem visual ou textual, ele penetrou seu olhar nas imagens em busca de seus indícios mais particulares, contextuais entrelaçando tempos e memórias centrados e descentrados, indo para muito além do que propôs Erwin Panofsky ao se apropriar do método de Warburg, limitando uma forma de olhar, ler e significar as artes visuais, método que se limitou à leitura da influência grega da proporção humana em comparação com as artes egípcia, bizantina e, especialmente, renascentista. A historiadora Luciene Lehmkuhl em sua resenha O lugar da imagem na reinstalação warburguiana sobre o livro de José Emilio Burucúa História, arte, cultura: De Aby Warburg a Carlo Ginzburg nos ajuda a compreender de forma mais didática alguns caminhos para o método de Warburg, que se organiza a partir do "uso da imagem, sua relação com outras formas de registro do vivido e do imaginado, sua construção e sua leitura" (LEHMKUHL, 2005, p. 228). Segundo Lehmkuhl é a ênfase no visual o eixo central do método de Aby Warburg apresentado por Burucúa, nesse sentido "o método warburguiano baseia-se na acumulação de textos, imagens e ideias, em cuja articulação as imagens ganham status privilegiado" (LEHMKUHL, 2005, p. 230).

E embora reconheçamos a necessidade de em muitos momentos fazermos um percurso de remissão ao passado europeu e de suas produções artísticas icônicas, como pinturas, esculturas e textualidades, o fazemos com o propósito do cotejamento ao modelo do pensamento de Aby Warburg em sua análise acerca do movimento vivo presente nas referências da pintura $O$ nascimento de Vênus de Sandro Botticelli em comparação com as referências da Antiguidade. Ao tomarmos essa concepção o fazemos para estabelecer comparações não com o intuito da busca de um léxico dos traços iconográficos antigos, mas sim, para compreender a singular experiência da representação dos corpos brancos e negros na produção de imagens visuais e textuais, tendo a produção greco-romana e renascentista como uma referência mnemônica da experiência humana na relação que une um sujeito ao outro.

E como também nos orienta Philippe-Alain Michaud, Warburg "se volta para a Antiguidade a ponto de se identificar com ela, não é para encontrar ali um repertório de imagens, mas para injetar nela as fórmulas expressivas que representarão a vida" (MICHAUD, 2013, p 79). Desse modo ao viabilizarmos a comparação das imagens 
produzidas nos periódicos A Coisa, com cartoons e/ou caricaturas estadunidenses, textos, o cinema e as pinturas europeias do período renascentista ou de períodos anteriores e posteriores, o fazemos conscientes de que a relação estabelecida entre os autores dessas imagens do tempo presente (do tempo de produção e circulação do periódico elencado) podem ter sido viabilizadas pela relação da experiência contínua das identificações com o passado, ressignificado, residual e dialógico: intertextual. Seja essa experiência proporcionada pela prática empírica da observação, da difusão dos discursos hegemônicos, ou até mesmo pelas aulas assistidas pelos caricaturistas do periódico $A$ Coisa no banco escolar do Liceu de Artes e Ofícios da Bahia ou na Escola de Belas Artes de Salvador. ${ }^{3}$

A partir das imagens visuais presentes no periódico A Coisa, e dos diálogos que propomos entre elas com pinturas canônicas, cujas representações corpóreas evocam sentidos e memórias, apresentam contornos e expressam encanto ou desencanto, mergulhamos em uma proposta analítica cunhada por Warburg acerca das normas pictóricas e o seu papel imaginativo e reflexivo (WARBURG, 2012, p. 18) naquele que observa uma imagem. A partir de uma metodologia descritiva e atenta aos detalhes acessórios que propõe organicidade e a contemplação no modo de olhar, destacamos uma a uma dessas três imagens com o objetivo de desvendar suas fantasias e sentidos por detrás de suas alegorias, metáforas e intenções.

\footnotetext{
${ }^{3}$ Na edição d'A Coisa do dia 30 de abril de 1899, o gravurista Arthur, o Bohemio (Arthur Arezio da Fonseca) publica uma crônica satírica ilustrada com a representação de um corpo feminino branco nu contra o encosto da cadeira na capa do jornal. A crônica recebe o título O Modelo. Nesta crônica, Arthur Arezio descreve uma cena na qual uma moça estaria sentada no quarto do narrador a falar seus pensamentos a respeito da grande arte Grega e Romana. Neste texto fica evidente a importância que Arezio dá ao mundo que ele chama de Antigo, e à arte que ele toma enquanto prodigiosa. Arhtur Arezio tem plena consciência dos cânones da pintura Greco-romana e parece desconhecer as artes Africanas e Orientais enquanto precursoras na representação do corpo nu. Leiamos o texto transcrito na íntegra: "O Modelo Só, no meu quarto, Dina, a mais encantadora das horizontais, sentada numa cadeira, refletia: Desde os primeiros tempos da pintura que o estudo do nu foi sempre admirado... Na Grécia e em Roma celebrados mestres escultores cinzelaram Venus, Cupido, Psyché e outros prodígios de arte, sem ao menos pôr-lhes umas saias ou uma tanga... Nú, inteiramente nú, mui raro é o pintor que se ocupa deste estudo... o fraco deles é pela natureza morta... ora, morta a natureza me causa até aborrecimento... Eu tenho servido de modelo, poucas vezes... E não me mostro a qualquer pinta-monos, completamente nua, porque eles não sabem fazer um esboço... portanto, só os contentos da cintura para baixo... mas, se reconheço ser um pintor forte... então, nesta posição, ele não perderá um só traço... todas as minhas formas estão á vista; eu serei para ele o modelo dos modelos. Arthur, o Bohemio. (A COISA, 30 abr. 1899, ano. 2, n. 88, p. capa)
} 


\section{A Coisa e suas xilogravuras}

A Coisa é um jornal ilustrado que começou a circular na cidade de Salvador, na Bahia, no dia 30 de agosto de 1897, e foi interrompido com a sua última edição no dia 8 de outubro de 1904. Nos desperta atenção o fato de, mesmo diante da modernização do sistema de editoração de impressos ilustrados no Brasil e na Bahia do seu período, A Coisa manter a produção de imagens xilográficas em grandes e pequenas dimensões, a depender do lugar em que são publicadas nas páginas do periódico. Essas imagens visuais são exibidas ora em suas capas, ora em páginas secundárias. A produção dessas imagens é quase artesanal, feitas a partir de matrizes gravadas em casca de cajazeira. Nossa atenção para o repertório de imagens produzidas pelos editores d'A coisa se volta ao fato de essas imagens visuais e, também, as imagens textuais/metafóricas conter uma pluralidade de representações étnicas de negros a compor o imaginário de uma sociedade atuante na Bahia de 1897 até 1904.

É o dia 10 de setembro de 1904, faltam poucos dias para o final do inverno no hemisfério Sul. O Brasil tem o seu quinto presidente da República Federativa, o descendente de portugueses, Francisco de Paula Rodrigues Alves (1848-1919) do Partido Conservador Republicano. Neste período o País enfrentava os desafios relacionados às doenças endêmicas e epidêmicas, como a varíola, a cólera e a peste bubônica. Por essa razão, políticas sanitárias foram encabeçadas pelo ministro da Saúde, Oswaldo Cruz (18721917). A Bahia, por sua vez, experimentava os primeiros meses com um novo governador do Estado, José Marcelino de Sousa (1848-1917) apoiado pelo seu antecessor, Severino Vieira (1849-1917) do Partido Republicano, e também pelo setor agroindustrial e pela elite baiana. Severino Vieira havia deixado o governo devastado por sua política de austeridade com crise financeira e atrasos no pagamento do funcionalismo público que chegava há oito meses sem receber salários (MELLO; BATALHA, 1990).

Apesar da preocupação iminente relacionada ao acometimento público de qualquer uma das doenças citadas, as políticas neste contexto da década de 1904 buscavam a modernização e a industrialização das cidades brasileiras, começando pelo Rio de Janeiro até as províncias potencialmente desenvolvidas pela economia do café e da possibilidade de industrialização do setor primário. 


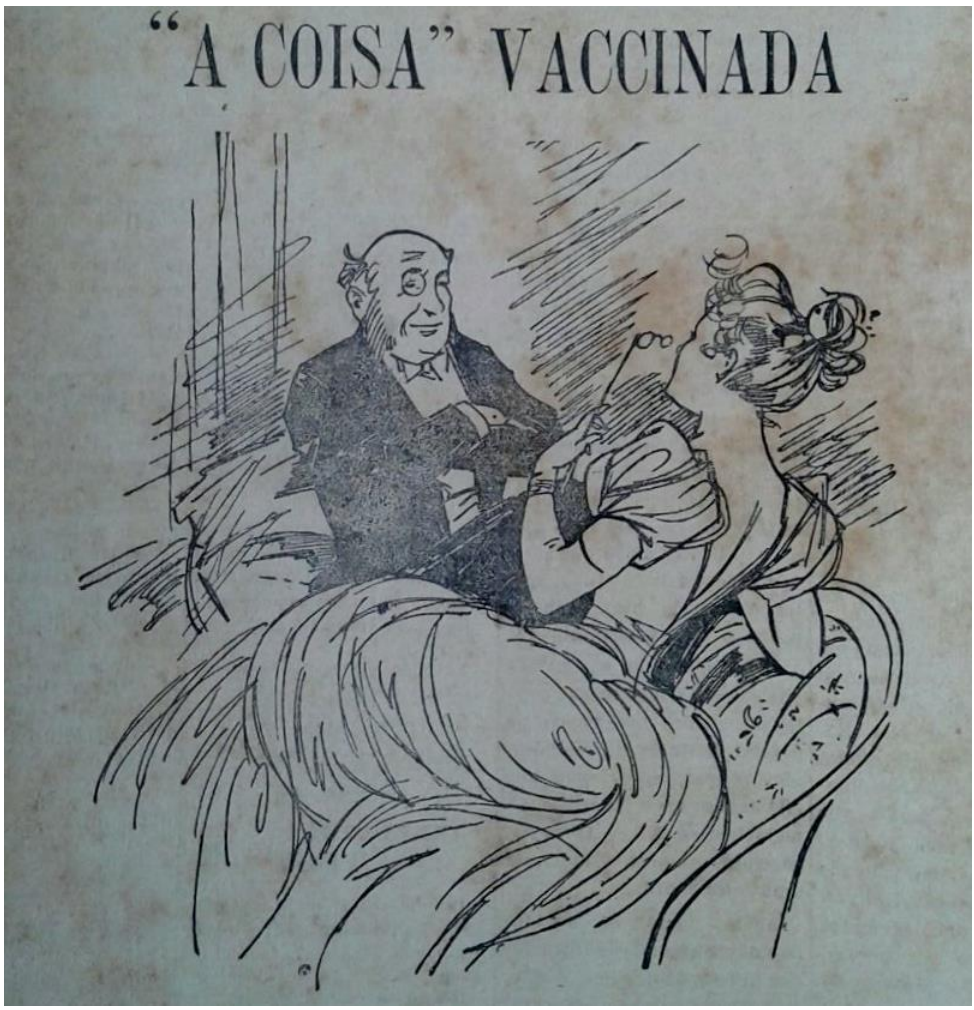

Fig. 1. FONSECA, Arthur Arezio. A Coisa vaccinada. 1904.

Impresso, (xilogravura em casca de cajazeira sopre papel pardo, preto) s/d.

A Coisa - Biblioteca Pública do Estado da Bahia, Salvador

Fotografia nossa - Leandro Arraes (tratamento de imagem)

No dia 10 de setembro de 1904 a Bahia publicou uma nova edição do semanário $A$ Coisa, depois de uma difícil temporada de irregularidades e o hiato de suas edições. Vinte e um dias depois desta publicação baiana, o Congresso Nacional do Brasil aprovaria a Lei da Vacina obrigatória contra a varíola, e trinta e um dias depois, em 10 de novembro do corrente ano, seria deflagrada na cidade do Rio de Janeiro, a Revolta da Vacina. O país e a Bahia estão às voltas com as questões epidêmicas. A capa do impresso traz a manchete: ““A Coisa' vaccinada” (A COISA, 10 set. 1904, ano 8, n. 2, p. capa) com a ilustração de uma dama no interior de um ambiente de luxo, sentada em um sofá canapé, vestida com um longo vestido armado e acinturado, e com generoso decote nas costas. A dama possui pulseiras no braço esquerdo e presilhas a prender o seu cabelo ondulado e claro com um coque. Ela segura com a mão esquerda, de forma delicada seus óculos lornhons enquanto conversa com um senhor de barba hirsuta e calvo, vestido com terno escuro, camisa clara 
e gravata borboleta. Acreditamos estarem em um consultório médico. Abaixo da imagem aparece o seguinte texto:

A vaccina contra a peste já descambou o terreno utilitário para o da troça e do... luxo!

Effectivamente, hoje em dia, há muito quem se vaccine, por uma ou por outra coisa, ou mesmo por ambas as coisas.

No caso de ambas as coisas, estamos nós, os d'A Coisa, que fizemos vir em casa um Esculapio, para injetar-nos um pouco de soro... n'A Coisa (A COISA, 10 set. 1904 , ano 8 , n. 2, p. capa).

A imagem e o texto não recebem assinaturas. Porém, acreditamos que a autoria da imagem seja do gravurista baiano Arthur Arezio da Fonseca e de outros colaboradores eventuais do periódico. Muitas imagens como esta se repetem ao longo das edições d'A Coisa, são representações visuais e pluralizadas, principalmente de corpos femininos brancos, ou seja, gravuras que não possuem entintagem no interior da região do corpo. Em sua maioria, essas imagens representam corpos femininos durante o cuidado da toalete, no interior privado de ambientes domésticos; são corpos cobertos com vestimentas luxuosas, no repouso de mobiliários exclusivos, acolchoados, estão a nos fazer pensar na ideia do repouso com movimentos singelos e contidos. Ao considerarmos as concepções de Edmund Burke, poderíamos entender que os sentidos de belo são evocados por essas imagens, que nos prendem os olhos com vagar, contemplação, admiração e o desejo de também nos identificarmos com ela por desejarmos a calma e a ponderação do corpo e dos gestuais.

Há também a representação de damas brancas e nuas, que nos faz remeter à obras plásticas de pintores que se tornaram referência de modos de representar o nu, os gestos e as poses, tais como Henri de Toulouse-Lautrec (1864-1901); Francisco de Goya (1746-1828), Jules Joseph Lefebvre (1836-1911), Diego de Silva Velázquez (1599-1660), Rembrandt Harmenszoon van Rijn (1606-1669), Édouard Manet (1832-1883), Edgar Degas (1834-1917), Tiziano Vecellio (1473/1490-1576), Jean-Auguste Dominique Ingrës (17801867), e Sandro Botticelli (1445-1510).

Das oito páginas lançadas pelo periódico nesta edição especial de regresso, sete páginas são dedicadas aos assuntos em torno da peste bubônica; são poemas, chistes, crônicas, e duas imagens, sendo uma caricatura de um casal de negros no ambiente do 
lar, na quarta página, denominada por Amor... Vestido (fig. 2), título homônimo do texto que a acompanha; e o retrato da pulga transmissora da peste bubônica, na quinta página. A contracapa do periódico é preenchida por reclames sem relação com a peste.

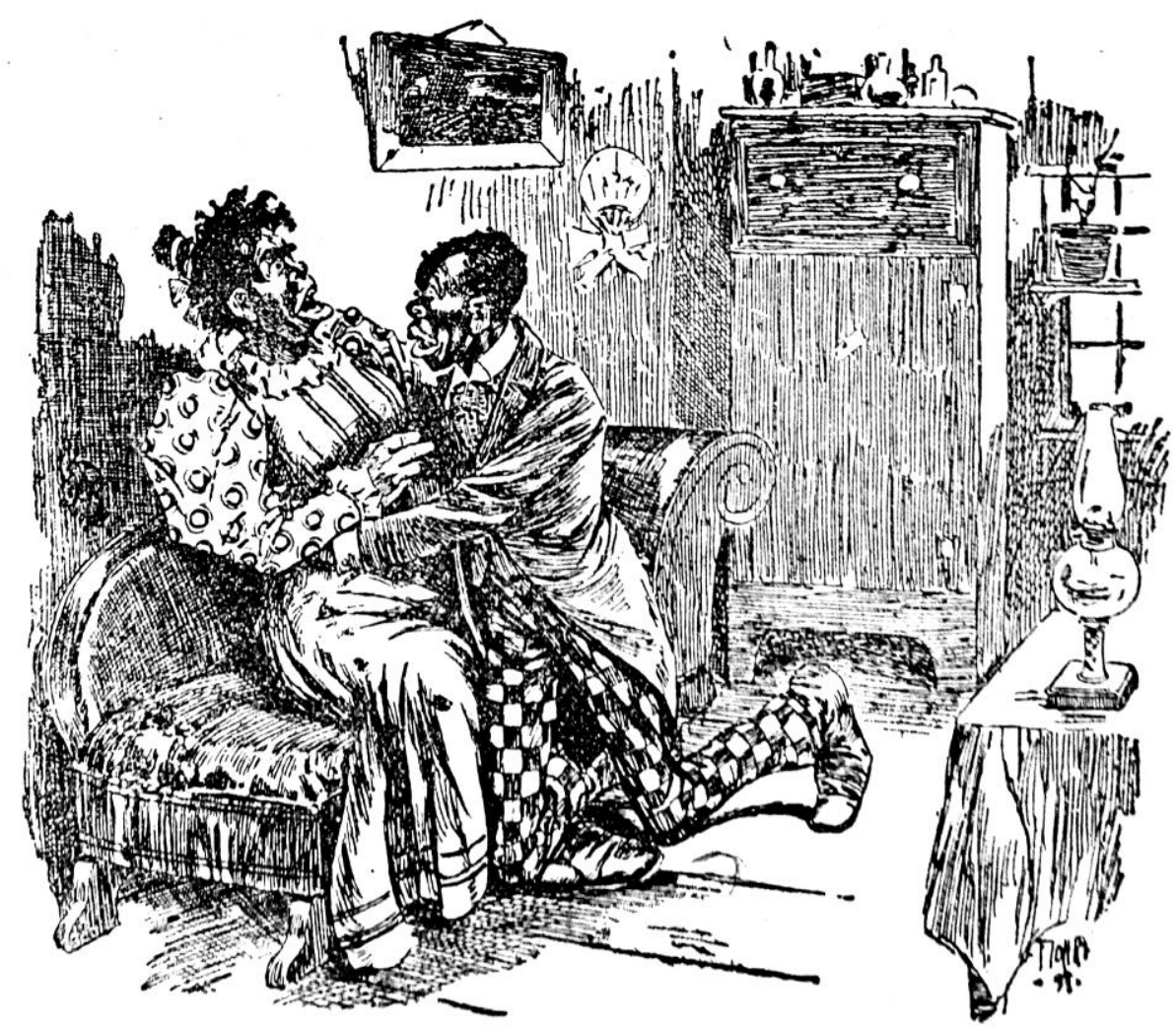

Fig. 2. SEM AUTORIA. Amor... vestido. 1904.

impresso, (xilogravura em casca de cajazeira sopre papel pardo, preto) s/d. A Coisa - Biblioteca Pública do Estado da Bahia, Salvador Fotografia nossa - Leandro Arraes (tratamento de imagem)

Das inúmeras imagens publicadas no impresso A Coisa, chamou-nos atenção, inicialmente, esta figura Amor... Vestido (fig. 2), que nos traz a representação de um casal de negros no interior do ambiente doméstico, uma novidade, a considerar que, cenas no ambiente privado publicadas n’A Coisa são reservadas, geralmente, às representações dos corpos brancos. Observemos que as faces das duas personagens nesta imagem não são entintadas, são iluminadas, talvez pela técnica do esfuminho, recebem entintagem nas bochechas, queixos, sulcos e são iluminados pela ausência de cor na região central dos rostos e testas. A observação e leitura dos fenótipos nos oferecem suas credenciais 
negras, a textura do cabelo crespo, o nariz negroide, as mãos, orelhas e pés grandes. A imagem traz consigo o seguinte texto:
AMOR... VESTIDO
Já se foram, felizmente, os omissos tempos da barbaria, em que o captiveiro tinha as honras de uma instituição.
Hoje, qualquer cidadão, da côr de azeviche, rolador de pipas no cães de Santa Barbara, aos domingos mette-se no uniforme da Festa do Bomfim e vae á casa de sua Ella, uma respeitabilíssima preta, que, nos dias uteis, ganha a vida honradamente, vendendo côcada e doce de banana na porta do armazém do Chico.
De trajes mudados, com ares de dona, a matrona creoula, assentada sobre um divan, recebe o cumprimento do seu Adonis preto, que se curva aos seus pés, enlaça-a nos braços, abre a bocca e fica toda...babado (A Coisa, 10 set. 1904, ano 8, n. 2, p. 4).

Com um olhar atento e treinado, se percebe na imagem a ausência do preenchimento da cor preta, para representar uma personagem branca, ou o preenchimento com esta mesma cor para a representação de um corpo negro. Mas, como buscar o meio tom? Como representar os diferentes matizes e gradações de tons de pele de brancos e negros em imagens monocromáticas? No segundo momento, é possível alcançarmos as ideias acerca dos matizes a partir da leitura e compreensão dos textos que norteiam as imagens ou acompanham as páginas do jornal. São os textos, em muitos momentos, a nos falar mais sobre a imagem dos negros que as próprias imagens visuais, que n’A Coisa trazem mais representações plásticas de corpos brancos em comparação ao número de evidências visuais dos corpos negros.

O aprimoramento das técnicas de reprodução de imagens em impressos permitiu aos gravuristas o desenvolvimento de várias soluções para que se alcançasse o meio tom, seja pelo chanfrado, na forma mais clara, mais escura ou esmaecida, seja pelo uso de linhas e outros grafismos que sugerem diferentes texturas e consequentemente diferentes tons para as superfícies representadas. Outro aspecto que auxilia na busca pelo matiz é o reconhecimento e a discussão em torno das questões raciais vigentes no período da Primeira República. Conscientes dos discursos sobre raças, os gravuristas, artistas, desenhistas e anatomistas, atentos aos detalhes do corpo, evidenciavam em seus traços os fenótipos dos corpos a que representavam, e desse modo construíam aproximações tipificadas ou não dos índios, dos negros e dos brancos. 
A leitura das imagens não se encerra apenas na observação exclusiva das imagens. Para o entendimento das representações dos matizes é necessário que se faça leituras das imagens aliadas aos seus contextos de produção e circulação, suas disposições nas páginas do jornal em sua integração com os textos que as circundam e com os demais assuntos tratados na mesma publicação. Assim, texto e imagem, ao serem interpelados, falam sobre os tipos de corpos e as peles negras produzidos nesses impressos; sobre os traços e formas concebidos, os lugares ocupados e o destaque nas páginas; as motivações para que fossem produzidas as imagens; quem as realizava, e em quê ou em quem se inspirava para produzi-las; que tipo de tensões essas imagens representavam e traziam para o contexto social e a imprensa no período de sua veiculação.

Embora publicada na Bahia do princípio do século XX, nos desperta atenção o fato de essa imagem (fig. 2) nos remeter ao imaginário norte-americano do blackface e de todo o conteúdo racial e tenso impresso por essa prática segregacionista da política estadunidense durante a era Jim Crow (876-1965) e dos Black Codes (1800-1866), que restringiam o convívio entre negros e brancos e determinavam espaços delimitados para cada um desses grupos de modo que eles não se misturassem. Ao nos propormos realizar a descrição genérica da imagem Amor... Vestido (fig. 2), conseguimos captar a aura ambígua na qual ela foi criada para também despertar um sentindo ambíguo em seus leitores. Notamos que a mulher negra recupera elementos mnemônicos da iconografia estadunidense da segunda metade do século XIX até o princípio do XX, quando a cultura popular nos Estados Unidos vai produzir uma gama de impressos diários, revistas e imagens com conteúdo cômico retratando o cotidiano.

A mulher negra da imagem d'A Coisa não recebe um nome, é uma Ella qualquer, “uma respeitabilíssima preta, que, nos dias uteis, ganha a vida honradamente, vendendo cocada e doce de banana na porta do armazém do Chico" (A COISA, 10 set. 1904, ano 8, n. 2, p. 4). Quando não é denominada preta recebe o qualitativo de crioula. O texto sugere que Ella está bem vestida para sair com o seu "qualquer cidadão, da cor de azeviche" (A COISA, 10 set. 1904, ano 8, n. 2, p. 4), o texto nos faz entender que eles parecem pretender a Festa do Bonfim. A cena, embora esteja localizada no interior privado de uma casa, não nos transmite a afeição de um casal enamorado, porque as personagens são 
desenhadas a partir de um instante-tipo que capta e potencializa a diferença tida como mais grosseira dos negros em comparação aos brancos: o cabelo crespo dela está arrepiado e preso em pequenos montinhos de modo desajeitado, os olhos arregalados dos dois quase saltam das suas faces, as orelhas enormes, os lábios grosseiros e a boca animalesca de ambos provocam qualquer reação de estranhamento, menos de comoção ou afeição.

Ao retomarmos as ideias de Edmund Burke acerca das sensações provocadas pelo belo e pelo sublime, é como se, ao observarmos essa imagem (fig. 2), e em seguida a ilustração Cleveland's "great and good friend" com a representação de Queen Liliokalani (fig. 3), fossemos convidados a experimentar a mesma experiência narrada por Frantz Fanon ao ser surpreendido pelo olhar de uma criança com sentimentos de autopreservação, terror e medo ao observar um negro - "Mamãe, olha o preto, tenho medo!"'(FANON, 2008, p. 106).

A imagem não provoca a simpatia, tal como nos poderia ter alertado sobre ela Edmund Burke. Ao percorrermos com os olhos os traços da gravura, devemos nos ater aos detalhes da desproporção dos olhos e das orelhas, e remetermos à concepção de Umberto Eco a respeito das proporções e simetria das partes e das esculturas, ou seja, nos parece que o produtor da imagem Amor... vestido (fig. 2), embora seja um conhecedor das técnicas de representação do belo, faz opção pelos sentidos que possam provocar o terror, o que nos faz entender que a imagem do casal de negros tenha sido feita para o riso e/ou o estranhamento, e não para a contemplação e, tampouco, para a identificação de seus leitores. É um casal improvável, criados para que o leitor branco possa rir das diferenças que os distanciam deles.

A nossa personagem Ella nos faz remeter às personagens domésticas chamadas de Mammys nos Estados Unidos, ambas se vestem com longos vestidos xadrez com babados, são cheias de corpo, rostos ovalados, olhos saltados, cabelos protegidos por turbantes ou presos com presilhas em pequenos montinhos. As Mammys são trabalhadoras, assim como Ella, mas elas não acumulam renda, não possuem famílias em suas representações; as famílias delas são seus senhores, que não as reconhecem como tal. As Mammys não namoram, são boçais, não têm vida nem vontades próprias, elas 
apenas atendem as expectativas dos outros. Talvez esteja ai a primeira diferença entre Mammy e Ella, pois Ella, enquanto textualidade esta a babar por seu Adonis negro, ela sente, ainda que seja por meio da visão de quem materializa a sua representação. A imagem e o texto no contexto do Brasil nos falam que a crioula tem fogo, ela sente, está babada.

O modo com que artistas brancos se apropriaram da cultura dos negros da diáspora africana nos Estados Unidos, no Brasil e em todos os países colonizados, permitiu que eles criassem imagens com personagens selvagens e boçais a seus modos, a partir do seu imaginário sobre aqueles negros que eles não conheciam. Os lábios, pés, mãos, narizes, orelhas monstruosos são apenas elementos sobrepujados para depreciar os negros e fazer o branco rir, são elementos externos que fazem parte da estrutura ideológica do racismo, da implantação da eugenia, e das políticas de embranquecimento e de aniquilamento da identidade corporal dos negros. A imagem de Ella e do seu Adonis negro também nos faz acessar outra imagem posterior a esta, praticamente idêntica na sua alegoria, a atriz norteamericana, Judy Garland (1922-1969) interpretou uma negra a partir da prática do blackface para uma cena do filme musical, Everybody Sing (1938), dirigido pelo cineasta também norteamericano, Edwin L. Marin (1899-1951). No Brasil o filme foi traduzido para Diabinho de Saias.

Na cena do controverso blackface, Judy Garland teve partes do corpo colorido de preto, incluindo a face, os lábios aumentados por batom vermelho, e fez uso de peruca ao estilo dos cabelos crespos e presos de nossa Ella, e usou um vestido com estampas de grafismos quadriculados ao estilo Mammy. A personagem de Garland também se utilizou de sotaque e de um inglês coloquial para a representação do negro boçal.

Ella se veste e tem os fenótipos semelhantes a personagem havaiana Queen Liliokalani (fig. 3), uma negra que vende jornais de porta em porta, representada pelas ilustrações de humor assinadas por George Benjamin Luks (1867-1933). A ilustração foi publicada em 1899 na segunda página da revista de humor norte-americana The Verdict, que teve circulação entre os anos de 1898 até 1900, com a colaboração efetiva de George Lucks. 


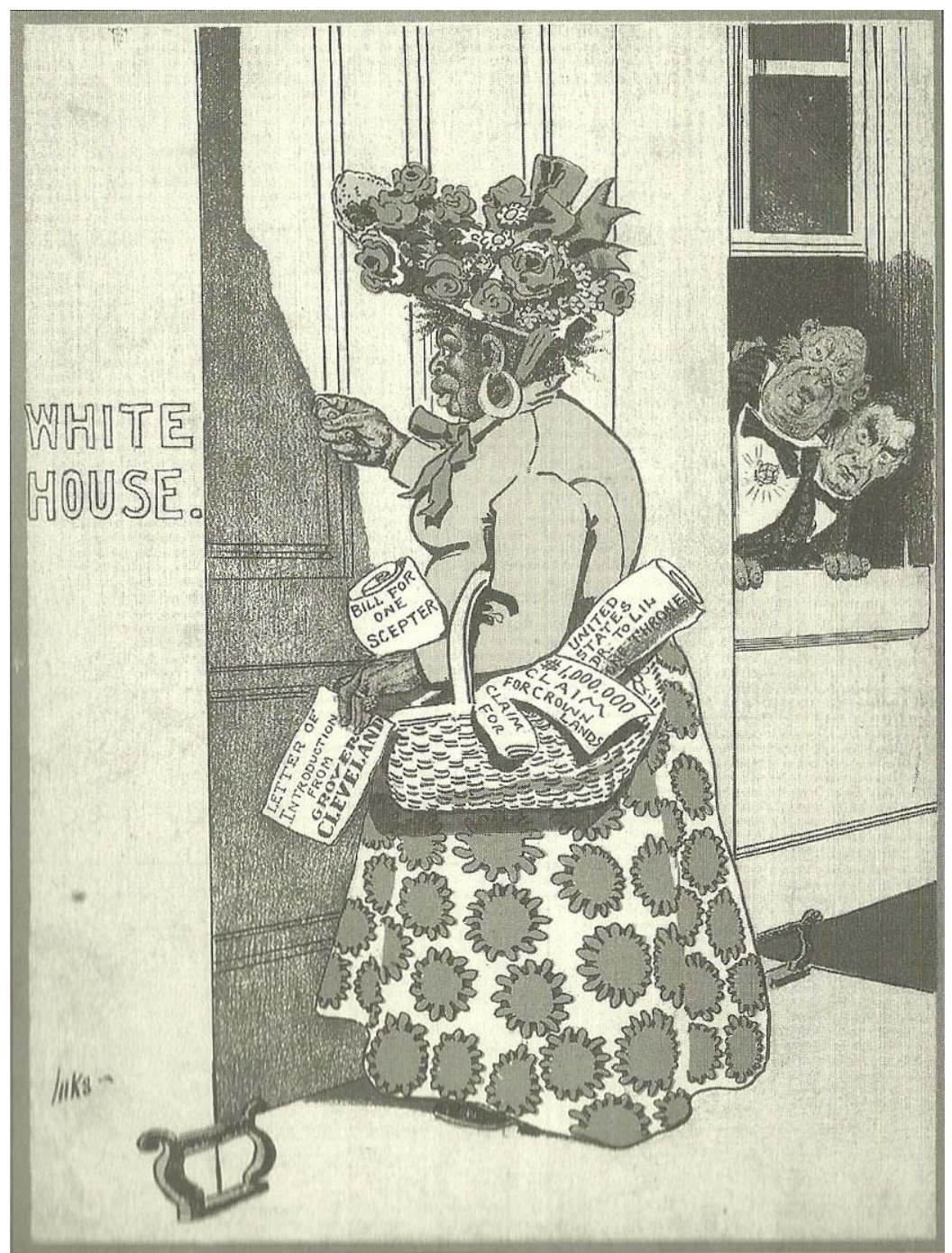

Fig. 3. LUCKS, George Benjamin. Cleveland's "great and good friend”. 1899. Impresso, (litografia sobre papel pardo, preto) s/d.

Verdict, 16 jan. 1899, p. 2

Biblioteca Pública de Nova Iorque, New York Aston, Lenox and Tilden Foundation

Dispersa, Liliokalani é observada por dois homens brancos, sendo um calvo com rosto marcado por sinais do tempo, rechonchudo e com papada protuberante, e o outro com rosto reto e magro e sobrancelhas espessas. Ambos os homens demonstram feições espantadas pela audácia de Liliokalani em transpor os limites dos Black codes para vender jornais em um condomínio de brancos. Até mesmo a profissão de nossas personagens se aproxima, Ella é vendedora nas ruas da Bahia, contudo, na Bahia não há Black codes, há hierarquias. 
Ao nos atermos a representação de Liliokalani na revista The Verdict, essa nos desperta atenção pelo seu conteúdo humorístico, provocado pela desproporcionalidade na região dos ombros, dos olhos, do nariz, dos lábios, da boca, dos dedos e das mãos, fazendo-nos acessar uma composição bestializada e caricatural pelo uso das estampas e o laço grandiloquentes na vestimenta, e o chapéu com o motivo de um buquê de rosas. Produzida por George Luks, essa talvez seja uma imagem cuja tentativa devesse ser a de subverter a imagem daquela que seria a primeira e última rainha regente da monarquia havaiana. A personagem aparece em quadrinhos sequenciados e também em páginas de edições avulsas da revista The Verdict. Apesar de usar do chiste e da ironia para satirizar a relação do governo norte-americano para com o Havaí, Luks reitera o olhar tipificado e leva os leitores desta imagem a se distanciarem afetivamente da rainha havaiana nascida com o nome Lydia Lili'Loloku Walania Wewerhi Kamaka'eha. Ao longo da sua existência, Lili'uokalani, nome real, recebeu vários nomes, com destaque para Lydia K. Dominis e também Lydia Kamaka'eha Paki.

A revista humorística estadunidense The Verdict tem o tempo de duração semelhante ao da revista baiana $A$ Coisa, ambas iniciam suas atividades nos últimos anos do século XIX e atravessam a virada do século, embora não consigam transpor o limite temporal da primeira década do século XX. Desse modo entendemos se tratar de duas revistas de contextos contemporâneos.

No Brasil os impressos ocupavam lugar de prestígio desde os tempos do Império, reconhecidos enquanto objeto de circulação de ideias, e no período de atividade do impresso A Coisa, no contexto que atravessa o Império, o Abolicionismo e a Primeira República, dentro da segunda metade do século XIX até o início do século XX, já existiam na Bahia, periódicos e diários de importância estimada, tais como O Diário da Bahia, O Jornal da Bahia e o Correio da Bahia, com circulação regular e expressiva força política.

A partir da leitura da obra Nação e cidadania no Império: novos horizontes organizada por José Murilo de Carvalho, entendemos que a opinião de grupos segmentados, mantinham sob seus domínios jornais, influência política e acesso aos espaços privados como saraus onde declamavam suas poesias com teor ideológico e pedagógico, e também espaços públicos como a tribuna para a difusão de ideias e 
saberes. A utilização desses espaços públicos, de acordo com Carvalho, foi perdendo espaço para os periódicos e diários com linguagem mais acessível e alcance mais amplo na difusão das ideias (CARVALHO, 2007). Segundo Tania Maria Tavares Bessone da Cruz Ferreira, era uma tendência "o estabelecimento de uma imprensa periódica de opinião" e, embora redatores e escritores ainda não tivessem o status de editores, e mesmo estando eles diante das restrições da censura, "escreviam libelos e defesas de suas posições políticas, fazendo ecoar novas ideias através de seus impressos" (FERREIRA, 2007, p. 190). Desse modo demarcavam ideologias “e procuravam propalar conceitos que tinham objetivos políticos e pedagógicos" (FERREIRA, 2007, p. 190).

No contexto de circulação d'A Coisa entendemos que, de um lado, ainda se mantinha a imprensa caracterizada por palavras despidas da figuração das imagens, de circulação regular, diária, politizada e com linha ideológica bastante definida: ora um grupo de jornalistas disseminava suas teses em favor da República que, há menos de uma década havia se instaurado, ora outro grupo de ideais opostos defendia a conservação dos valores políticos centralizadores do Estado monárquico que acabava de ruir. Nesse bojo da imprensa baiana também havia espaço para os periódicos críticos, ilustrados, caricatos e literários com ou sem cor política definida, embora atravessados pela irregularidade de suas edições e circulação (TAVARES, 2008).

Os primeiros registros de jornais ilustrados com gravuras no território nacional se confundem com o nascimento da imprensa no Brasil. Com a leitura da obra de Orlando da Costa Ferreira tem-se a informação de que as primeiras imagens visuais difundidas nos impressos nacionais datariam de 1817, com o uso de pequenas vinhetas de caixa, politipagens ${ }^{4}$ e gravuras importadas da Europa. ${ }^{5}$ Esses usos se faziam nos territórios do Rio de Janeiro, Recife e Bahia. Apesar do uso de importações, Ferreira aponta que a

\footnotetext{
${ }^{4}$ Entendemos como sinônimos a politipagem, as figuras de caixa e as vinhetas.

5 Segundo consta na obra de Orlando da Costa Ferreira, a xilografia nordestina seria a continuação da xilografia portuguesa, diferenciando-se apenas na sua veiculação. O cordel nordestino seria também a continuação do folheto de feira português. Desse modo, o uso das gravuras na imprensa do Brasil parecia ser uma tentativa de eterno retorno do cancioneiro oral. Para ele os primeiros xilógrafos dos folhetos populares viviam dentro das próprias tipografias, e eram eles que desde a primeira metade do século vinham sendo responsáveis pela feitura de gravuras, ainda que de modo anônimo. A diferença das gazetas para as quais desenhavam e os folhetos de feira portugueses era o tamanho das gazetas, um pouco maiores ou a metade de uma folha de papel almaço (FERREIRA, 1994, p. 232-233).
} 
técnica do talho em madeira era praticada em Recife desde 1817, dirigida pelo cartógrafo carioca José Fernandes Portugal. ${ }^{6}$ É, no entanto, somente, a partir de 1822 que se reconhece o uso da xilogravura (gravura em madeira) produzida no Recife para ilustrar um periódico nacional, O Maribondo (RAMOS, 2014).

Se, de um lado, tem-se na pintura a diversidade temática na representação do conteúdo, na fotografia encontra-se o isolamento dos detalhes e a fragmentação icônica. Segundo Michaud "o caráter substancial dos corpos se refletia na estabilidade da representação [...] não há mais substância, mas fragmentos e sequências" (MICHAUD, 2008, p. 542). Entende-se, contudo, que é a partir do aperfeiçoamento da técnica de representação da imagem, que a transforma num serviço do conhecimento e da utilidade, que sua racionalização e aprimoramento das práticas de modelagem são realizados com cuidados mais específicos, dando a ela agilidade e generalizações temáticas, como o da produção do tipo racial puro, os registros da doença e do estigma e as representações dos fatos do dia-a-dia.

É, todavia, por meio da leitura de Warburg que nos tornamos atentos para o fato de que um poema, uma crônica e uma imagem podem sim estarem conectados pela emoção de quem os produziu, pelo senso estético, o contexto e as semelhanças com que foram tratados os seus motivos alegóricos (WARBURG, 2012, p. 62-63). As semelhanças transpõem os aspectos visuais da forma plástica, e a partir da memória inconsciente dos produtores, a criarem esculturas, textos ou imagens, nos revelam formas e gestos que denunciam "certa montagem do tempo" (DIDI-HUBERMAN, 2013, p. 193).

Segundo Georges Didi-Huberman, "Warburg teve que dialetizar constantemente o seu ponto de vista, fazer seu discurso involuir para a estrutura fatalmente ambígua dos anacronismos com que ele se confrontava em cada nível de análise" (DIDI-HUBERMAN, 2013, p. 193), e desse modo, entendemos que ao nos cercarmos dessas considerações para a compreensão analítica de corpos representados, também propomos a transposição dos limites do método comparativo da antropologia. Atemos-nos não ao

\footnotetext{
6 "Um dos primeiros fatos importantes da história da gravura no Brasil consiste num anúncio publicado na Gazeta de 31 de março de 1819 pelos editores dos Annaes das Sciencias, das Artes e das Lettras, a já citada revista portuguesa que vinha sendo publicada em Paris e de que era agente no Rio de Janeiro o livreiro e futuro impressor Manoel Joaquim da Silva Porto" (FERREIRA, 1994, p. 141-142).
} 
tempo, mas aos motivos, o conteúdo, o corpo e o seu contexto de produção, a pulsão, a forma, sua organicidade e a sua cultura (DIDI-HUBERMAN, 2013, p. 198-199).

Eis aqui, no fechamento destas proposições, o entendimento de que a partir de um olhar globalizante os povos costumam, para designar o feio, opô-lo ao belo, e, ainda, que um estudo mais apurado possa conduzir a uma espécie de autonomia do feio, este pode se transformar em algo tão rico e complexo que uma série de simples negações e/ou apropriações das várias formas de beleza (ECO, 2004). Mas, em outro aspecto, Frantz Fanon, questiona quem saberá dizer o que é a beleza, quando a questão está relacionada a visão de quem vê e do lugar que vê, quando num mundo branco "o preto é um animal, o preto é ruim, o preto é malvado, o preto é feio [mas pela] brancura que me calcina" (FANON, 2008, p. 107). Para Fanon, existe além de um esquema corporal e histórico-racial, um esquema epidérmico racial, em que o negro não é apenas responsável pelo seu corpo, mas por sua raça e por sua ancestralidade, da qual será sempre cobrado, seja por uma coisa boa o ruim, pelo que sua aparência logo apresenta ao outro (FANON, 2008, p. 105).

Em outra via do mesmo diálogo, tem-se a concepção material para definir e dissociar o belo do feio e vice-versa. A partir das reações sensíveis dos sujeitos sociais perante a imagem ou presença do que cada um desses conceitos lhes transmita, conforme a exemplificação de Hebert Read,

o homem reage à forma, superfície e massa do que se lhe apresenta aos sentidos, e certas distribuições na proporção da forma, da superfície e da massa dos objetos tem como resultado sensação agradável, enquanto a falta de distribuição acarreta indiferença ou mesmo desconfôrto (sic) positivo e revulsão. O sentimento de relações agradáveis constitui o sentimento de beleza; o sentimento oposto representa o da fealdade (READ, 1978, p. 20).

Há, entretanto, que ser insistente e perguntar ao espelho da Rainha se existiram belezas que transpunham os limites territoriais da Alemanha, ou até bem distantes das fronteiras territoriais europeias e nórdicas. ${ }^{7}$ Uma pergunta cuja resposta é revelada mais

\footnotetext{
7 Referência à personagem da Rainha má do conto A Branca de Neve dos Irmãos Grimm. Em sua edição francesa, a Rainha pergunta ao espelho se existe alguém no mundo mais bela que ela, e o espelho ao
} 
adiante, especificamente no início do século XX, momento em que neste espelho a imagem refletida anunciou um ideal de seleção para a purificação da excelência da raça ariana, considerada a raça-mestra pelos povos com ideal nazista.

\section{Conclusão}

É possível, portanto, apontar algumas considerações para à guisa de conclusão da reflexão desta nossa proposta. A técnica de produção de imagens visuais é capaz de auxiliar os produtores de imagens, na reprodução de representações com maior ou menor quantidade de conteúdos que alcancem uma ideia de verossimilhança e/ou realismo naquilo que é representado. Naturalmente, ao considerarmos as escolas de belas artes na Bahia, é possível entendermos que o saber dos alunos no contexto de produção do impresso A Coisa, especificamente no que concerne ao caricaturista Arthur Arezio da Fonseca - responsável pelas gravuras produzidas e selecionadas para essa análise - está relacionado ao inconsciente dos seus professores, e intimamente ligado aos ideais de valores europeus.

Arthur Arezio da Fonseca, contudo é um sujeito que nasceu e viveu na Bahia, uma testemunha viva do cotidiano de um Brasil bastante complexo, plural, miscigenado e, principalmente, diferente do imaginário de mundo europeu. Todavia, mesmo sendo Arezio um conhecedor das técnicas de produção de imagens e tendo a seu dispor novas técnicas de editoração de impressos com imagens, esse faz opção pela produção de xilogravuras, e ainda diante dessa opção e de todo o seu conhecimento técnico, Arezio reitera a excelência daquilo que ele chama de cânone grego e romano em suas produções; e, mesmo quando tem a possibilidade de produzir imagens dignificantes de negros, este opta por imprimir em suas gravuras a desproporção, apresentando sua

responder ao questionamento da Rainha, diz que, embora ela seja bela, há no mundo alguém ainda mais bela, e esse alguém é a Branca de Neve, cuja pele é tão alva quanto os flocos da neve. Entendemos, portanto, que nesse contexto do conto alemão, traduzido para diversos idiomas, e preservando o termo mundo em suas traduções, a beleza universal está associada ao tom de pele da personagem, de modo que o texto incita aos leitores interpretarem que, para ser a mais bela do mundo é necessário que a pessoa tenha o matiz de pele sem contrastes, ou seja, é preciso que a pele seja alva tal como o é também a personagem Escrava Isaura de Bernardo Guimarães, no Brasil (GUIMARÃES, 1875). Para mais ver: (GRIMM, 1976, p. 144-157); (GRIMM, 2010); (GRIMM, 1949, p. 244-252), (ESTÉS, 2005). 
dizer que, as proporções devem ser consideradas antes como um produto do entendimento do que como uma causa fundamental da beleza. A beleza foi compreendida como um valor ocidental, significado no passado pela filosofia e pela complexidade das culturas, mas que seus efeitos e atributos tomaram proporções de acordo com a denominação e a expansão territorial de uma cultura em detrimento de outras.

O belo enquanto conceito recebe significações e conotações distintas em épocas e pensamentos diferentes. No entanto, tem em si as concepções europeias que lhes dá caráter natural, universal e inerente às sensações mecânicas de quem o vê, sente e o atribui. Todavia ao refletirmos acerca do desenvolvimento das técnicas de produção de imagens, a partir de seus produtores, entendemos que eles são reiteradamente educados a ampliar seus conhecimentos técnicos, e se tornarem capazes de representar uma pluralidade de imagens visuais dos corpos brancos, fazendo com que essas representações provoquem em seus espectadores os mais diversos sentimentos, compreendendo especialmente os sentidos de belo, e estimulando identificações e a contemplação dos seus motivos, poses, gestos, afeições, e fenótipos. Enquanto, por outro lado, ao buscar a representação dos corpos negros, a técnica de produção de imagens aplicada por esses produtores, ainda se vê intermediada pelos conteúdos dos tipos raciais puros e/ou unificados, tipificados, grotescos, desproporcionais e que provoquem sensações de não identificação, riso, horror, terror, medo e distanciamento. 
A COISA. Salvador, ano 8, n. 2, capa, 10 set., 1904.

A COISA. Salvador, ano 8, n. 2, p. 4, 10 set., 1904.

BURKE, Edmund. Uma investigação filosófica sobre a origem de nossas ideias do sublime e do belo. Trad. Enid Abreu Dobránszky, Papirus: Editora da Universidade de Campinas, Campinas, 1993.

DIDI-HUBERMAN, Georges. A imagem sobrevivente: história da arte e tempo dos fantasmas segundo Aby Warburg. Rio de Janeiro: Contraponto, 2013.

DUROZOI, Gerard; ROUSSEL, André. Dicionário de Filosofia. Trad. Marina Appenzeller. 2. ed. Campinas: Papirus, 1996.

ECO, Umberto. Storia della bellezza. 2. ed. Milano: Bompiani, 2004.

ESTÉS, Clarissa Pinkola. Branca de Neve e os sete anões. In: ESTÉS, Clarissa Pinkola (Org.). Contos dos irmãos GRIMM. trad. Lia Wyler. Rio de Janeiro: Rocco, 2005.

EVERYBODY SING (Diabinho de saias). Diretor: Edwin L. Marin, produtor: Harry Rapf, EUA: Warner Bros. 1938. DVD, Archive Collection.

FANON, Frantz. Pele negra, máscaras brancas. Trad. de Renato da Silveira, Salvador: EDUFBA, 2008.

FERREIRA, Orlando da Costa. Imagem e letra: introdução à bibliologia brasileira: a imagem cravada. 2. ed. São Paulo: Editora da Universidade de São Paulo, 1994.

FERREIRA, Tania Maria Tavares Bessone da Cruz. Os livros na imprensa: as resenhas e a divulgação do conhecimento no Brasil na segunda metade do século XIX. In: CARVALHO, José Murilo de. (Org.) Nação e cidadania no Império: novos horizontes. Rio de Janeiro: Civilização Brasileira, 2007.

GRIMM. Blancheneige. In: GRIMM, Jacob. Conts. Trad. et préface Marthe Robert. Paris: Gallimard, 1976, p. 144-157. 
GRIMM. Fairy tales. [19--]. Disponível em: <http://sparks.eserver.org/books/grimmfairytales.pdf>. Acesso em 22 dez. 2010.

GRIMM. Sneewittchen. In: GRIMM, Jacob. Kinder-Und Hawsmärchen. München: Winkler, 1949, p. 244-252.

GUIMARÃES, Bernardo. A escrava Isaura. São Paulo: Martim Claret, 2005.

HEGEL, Georg Wilhelm. Estética: o belo artístico ou o ideal. In: OS PENSADORES. Trad. de Orlando Vitorino São Paulo: Nova Cultural, 1988.

HUME, David. Ensaios políticos, morais e literários. In: BERKELEY, George e HUME, David. Os pensadores. Trad. de Anoar Aiex, João Paulo Gomes Monteiro, Armando Mora de Oliveira. São Paulo: Nova Cultural, 1989.

KANT, Immanuel. Crítica da faculdade do juízo. Trad. Valério Rohen. Rio de Janeiro: Forense Universitária, 1993.

LE GOFF, Jacques. História e memória. Campinas, SP: Editora da Unicamp, 1994.

LEHMKUHL, Luciene. O lugar da imagem na reinstalação warburguiana. ArtCultura, Uberlândia, v. 7, n. 11, p. 227-232, jul./dez., 2005.

LIMA, Herman. História da caricatura no Brasil. 1v. Rio de Janeiro: José Olympio, 1963.

MELLO, Agenor Bandeira de; BATALHA, Sílvio. Cartilha histórica da Bahia: registro político do Estado. 5ed. Salvador: Edição do autor, 1990.

MICHAUD, Philippe-Alain. Aby Warburg e a imagem em movimento. Rio de Janeiro: Contraponto, 2013.

MICHAUD, Yves. Visualizações: o corpo e as artes visuais. In: CORBIN, Alain; COURTINE, Jean-Jacques; VIGARELLO, Georges (Orgs.) História do corpo: as mutações do olhar: século XX. Trad. Ephraim Ferreira Alves. Petrópolis: Vozes, 2008.

PANOFSKY, Erwin. Estudos de iconologia: temas humanísticos na arte do Renascimento. 2ed. Trad. Olinda Braga de Sousa. Lisboa: Editorial Estampa, 1995.

RAMOS, Everardo. Origens da imprensa ilustrada brasileira (1820-1850): imagens esquecidas, imagens desprezadas. Revista Escritos, Ed. Casa de Rui Barbosa, ano 3, n. 3. 
READ, Hebert. $O$ sentido da arte: esboço da história das bases dos julgamentos estéticos. São Paulo: IBRASA, 1978.

TAVARES, Luis Guilherme Pontes (Org.). Apontamentos para a história da imprensa na Bahia. 2ed., rev., e ampl. Salvador: Academia de Letras da Bahia, 2008.

VERDICT. Nova Iorque, ano 1, n. 2, p. 2, 16 jan. 1899.

WARBURG, Aby. O nascimento de Vénus e a primavera: Sandro Botticelli. Lisboa: KKYM, 2012.

Recebido em 28/03/2018 Aprovado em 30/07/2018 